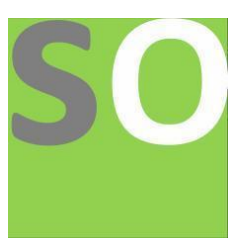

Article title: Molecular Docking and Admet Analyses of Photochemicals from Nigella sativa (blackseed), Trigonella foenum-graecum (Fenugreek) and Anona muricata (Soursop) on SARS-CoV-2 Target

Authors: OLUWASEUN TAOFEEK[1]

Affiliations: FEDERAL UNIVERSITY OF AGRICULTURE, ABEOKUTA[1]

Orcid ids: 0000-0002-3076-4648[1]

Contact e-mail: oluwaseuntosinn@gmail.com

License information: This work has been published open access under Creative Commons Attribution License http://creativecommons.org/licenses/by/4.0/, which permits unrestricted use, distribution, and reproduction in any medium, provided the original work is properly cited. Conditions, terms of use and publishing policy can be found at https://www.scienceopen.com/.

Preprint statement: This article is a preprint and has not been peer-reviewed, under consideration and submitted to ScienceOpen Preprints for open peer review.

Funder: NONE

DOI: 10.14293/S2199-1006.1.SOR-.PPKNVFY.v1

Preprint first posted online: 07 June 2020

Keywords: SARS-COV-2, 3CLpro, Nigella sativa, Trigonella foenum-graecum, Anona muricata, Molecular Docking, ADMET, COVID-19, coronavirus 


\section{MOLECULAR DOCKING AND ADMET ANALYSES OF PHYTOCHEMICALS FROM Nigella sativa (blackseed), Trigonella foenum-graecum (Fenugreek) and Anona muricata (Soursop) ON SARS-COV-2 TARGET}

Oluwaseun O. $\mathrm{T}^{1,2,4^{*}}$, Rahman S. $\mathrm{A}^{1}$, Alakanse S. $\mathrm{O}^{2}$, Akinloye O.A ${ }^{1}$, Ibrahim S. Z ${ }^{3}$, Makama, Y. A ${ }^{3}$, Bankole, O. $\mathrm{S}^{4}$

${ }^{1}$ Department of Biochemistry, College of Biosciences, Federal University of Agriculture, Abeokuta, Nigeria.

${ }^{2}$ Department of Biochemistry, College of Life Sciences, University of Ilorin, Ilorin, Nigeria.

${ }^{3}$ Department of Biological Sciences, Niger State Polytechnic, Zungeru, Niger State, Nigeria.

${ }^{4}$ Biochemistry Unit, Intellectual Harvarde Educational Services, Obada, Ogun State, Nigeria.

*Corresponding Author: Oluwaseun O.T. Department of Biochemistry, Federal University of Agriculture, Abeokuta. E-mail: oluwaseuntosinn@gmail.com. Phone: +2348148581075. ORCID:0000-0002-3076-4648

\section{ABSTRACT}

The novel severe acute respiratory syndrome coronavirus-2 (SARS-CoV-2) responsible for the 2019 coronavirus disease (COVID-19) has caused a global health challenge. The SARS-COV-2 main protease, 3CLpro/Mpro plays a critical role in the viral gene expression and replication and has been a major target for inhibiting viral maturation and enhancing host innate immune responses against COVID-19. In this study, we screened a library of 38 phytochemicals from Nigella sativa (blackseed), Trigonella foenum-graecum (Fenugreek) and Anona muricata (Soursop) - potent medicinal plants with reported antiviral properties - in a molecular docking protocol on 3CLpro using Autodock4.0 tool implanted in PyRx followed by docking validation and insilico absorption, distribution, metabolism, excretion, and toxicology (ADMET) evaluations. The docking results were visualized using Accelrys Discovery Studio and Pymol software. Among the 38 ligands screened, 19 showed significant interaction through non-covalent hydrogen bonding, hydrophobic, and electrostatic interactions with binding affinities from $-5.3 \mathrm{kcal} / \mathrm{mol}$ to $-8.1 \mathrm{kcal} / \mathrm{mol}$ indicating significant binding interactions at the active site binding pocket. Another important interaction observed in the study which mostly involve the transfer of charges was pi-interactions such as Pi-Pi interaction, Pi-Alkyl interaction, Pi-Sulfur interaction, Pi- Sigma, and Pi-Pi stacking. The docking results revealed that phytochemicals from $T$. foenum-graecum showed more 3CLpro inhibitory potential compared to those from $N$. sativa and A. muricata. Insilico ADMET evaluations for drug-like and lead-like characteristics however demonstrated that only 8 ligands - apigenin, kaempferol, luteolin, dithymoquinone, naringenine, nornuciferine, quercetin and nigellidine were actually drug-like; showed best activities against 3CLpro, and lack hepatotoxicity effects while none was lead-like. Insilico results of this study further suggested that drug 
repurposing candidates, remdesivir, indinavir,hydroxychloroquine, chloroquine and ritonavir,exhibited various interactions with 3CLpro. Hence, further in vitro and in vivo studies are proposed.

Keywords: SARS-COV-2, 3CLpro, Nigella sativa, Trigonella foenum-graecum, Anona muricata, Molecular Docking, ADMET

\section{Introduction}

The severe acute respiratory syndrome coronavirus-2 (SARS-CoV-2) responsible for the December 2019 coronavirus disease (COVID-19) first reported in Wuhan city of Hubei province in China was declared a pandemic by the world health organization on March $11^{\text {th }}, 2020$. As at $26^{\text {th }}$ May, 2020, there were 5,370,375 cases of COVID-19 in 216 countries and 344,454 confirmed deaths [1].

The SARS-COV-2 follows earlier emergence of the severe acute respiratory syndrome coronavirus (SARS$\mathrm{CoV}$ ) and the Middle East respiratory syndrome coronavirus (MERS-CoV) in 2003 and 2012 respectively. These enveloped viruses come under the family known as Coronaviridae, Sub-order Cornidovirineae \& Order Nidovirales [2] and have four genera: alpha, beta, gamma \& delta genera and are known to often cause cold \& respiratory diseases commonly in humans [3]. SARS-COV-2 like other coronaviruses, belongs to the beta genus genome and comprises a positive-sense single-stranded RNA having about thirty-thousand nucleotide in length and infects both animals and humans [3]. The genome of SARS-CoV-2 has fourteen open reading frames (ORFs) which have been elucidated to encode 27 proteins such that at the 5'-terminus, the orf1ab and orf1a code for two large polyproteins: pplab and ppla respectively [4]. These large polyproteins altogether comprise about two-third of the genome having 16 non-structural proteins (nsps). The coronavirus main protease, chymotrypsin-like protease, 3CLpro also referred to as Mpro is found to be integral to the expression of viral gene and replication and is being encoded by the nsp5 in the viral genome [5]. Functional proteins including RNA-dependent RNA polymerase (RdRp) and Helicase (Hel) are generated when 3CLpro cleaves the two large polyproteins. Furthermore, the papain-like protease (PLpro) cleaves the two polyproteins generating proteins required for virus replication. It also helps to strip ubiquitin thereby making coronaviruses evade the innate immune responses of the host [6]. The other ORFs are important for encoding structural and accessory proteins such as membrane protein (M), spike surface glycoprotein $(\mathrm{S})$, nucleocapsid protein $(\mathrm{N})$, and small envelope protein $(\mathrm{E})$ [5].

Currently, there is no approved drug for COVID-19 as at May 2020. However, drug repurposing and supportive strategies have been utilized in the treatment of COVID-19 patients. Such drugs include remdesivir, chloroquine, hydroxychloroquine, ritonavir, indinavir, ribavirin, \& several others which are under clinical trials to ascertain their efficacies for use in treatments. The essential roles played by 3CLpro and PLpro make them good targets in inhibiting viral maturation and enhancing host innate immune responses against COVID-19 [7]. Computational methods are essential approaches often found useful in 
economizing and accelerating drug discovery and development compared to the more time-consuming and costly process of experimental evaluations.. These methods have been utilized to screen several potential drug candidates and have played a role in predicting their pharmacological/pharmacokinetics profile which defines their absorption, distribution, metabolism and excretion, and toxicities (ADMET). In silico ADMET filters are fully considered now to be fully integrated right from the early stages of drug discovery and development [8].

The increasing advocacy for the use of herbal products in various diseased conditions has gained popular opinion in recent times. Several herbs and herbal products are also progressively being screened for their efficacies in the face of the current pandemic as the world thirst towards a cure for the disease. Medicinal plants or herbs have been used for thousands of years dating back to the times of the Bible and Quran. According to Ahmad et al. [9], Nigella sativa also known as blackseed or black cumin is an important medicinal plant that contains thymoquinone as the main active component. The other important constituents include dithymoquinone, p-cymene, thymohydroquinone, carvacrol, isoquinoline, 4-terpineol, sesquiterpene, longifolene, $\alpha$-pinene, $\alpha$-hederin, t-anethole, pyrazol alkaloids, and thymol [9]. N. sativa has been utilized as antiallergic [10-112], anticarcinogenic [9, 13-14], antidiabetic [15-19], antihypertensive [20], antimicrobial [9], antiviral [21] and antioxidative [9]. Another important medicinal plant commonly used in traditional medicine is Trigonella foenum-graecum (Fenugreek). Its seed and leaves are used for food and traditional medicine all over the world. Its biological actions include antiviral [21], hypoglycaemic and antidiabetic [2223], antiulcerogenic [24], hypocholesterolaemic [25-26], antinociceptive [27-28] and also possesses immunostimulatory effects [29]. It has also proven to be antioxidative [21, 30], antihypertensive [31], hepatoprotective [32], and chemoprotective [31, 33]. Soursop (Annona muricata) also known as graviola, gyanabama and sirsak is widely distributed in the tropical and subtropical parts of the world [34]. The plant have been used in traditional medicines against diseases such as arthritis [34-35], cancer [36-38], parasitic infections [39-41], antiviral [21, 43] neuralgia, diarrhea, fever, dysentery, malaria and to elevate the milk level of a mother after childbirth [34].

With the aforementioned biological activities of Nigella sativa (blackseed), Trigonella foenum-graecum (Fenugreek) and Anona muricata (Soursop), we aimed to perform a set of computational virtual screening techniques with molecular docking in addition to ADMET evaluations in this study to assess the inhibition of the SARS-COV-2 main protease, 3CLpro with small molecules from the medicinal plants. Compound interaction modes, binding energy at the active site, and ADMET evaluations were analyzed and ranked with the most promising compounds proposed as inhibitors of SARS-CoV-2 main protease. 


\section{Materials and Methods}

\subsection{Literature search and compound selection}

Compounds from Nigella sativa (blackseed), Trigonella foenum-graecum (Fenugreek) and Anona muricata (Soursop) with biological activities including antiviral properties were searched for and selected both from the phytochemical and ethnobotanical databases (https://phytochem.nal.usda.gov/phytochem) [21], and Literatures $[34,42]$ and were then examined in the next stage of our study.

\subsection{Preparation of protein/receptor and ligands.}

Crystal structure of SARS-COV-2 main protease, 3CLpro (PDB ID: 6LU7) was retrieved from the Protein Data Bank (http://www.rcsb.org) [44]. Using the online tool, protein-ligand indentifier profiler (PLIP) [45], the active site of the SARS-CoV-2 main protease was identified. The protein preparation step included the removal of water molecules using Accelrys Discovery Studio software [46]. This was followed by the making of the macromolecule using the PyRx software [47] which included addition of hydrogen atoms, updating and filling missing side chains residues, optimizing the hydrogen bonds, adding formal charges and then optimizing at neutral pH. The 3D SDF ligands (Figures 1-3) were downloaded from Pubchem database [48] while those of experimental and investigational drugs: hydroxychloroquine (DB01611), remdesivir (DB14761), ritonavir (DB00503), Indinavir (DB00224), and chloroquine (DB00608) were downloaded from the DrugBank [49]. They were minimized and converted into PDBQT in the PyRx virtual screening tool.

\subsection{Molecular Docking and Validation of Docking Protocol}

Using the AutoDock Vina wizard [50] implanted in PyRx for the docking procedure, the ligands and repurposed experimental drugs were screened for their interactions with the active site of the protease. A total of 9 ligand poses were assessed at the active site. The best pose was taken to be the pose with the lowest binding energy in $\mathrm{kcal} / \mathrm{mol}$. Docking results were exported away from PyRx, and receptor-ligand interactions analyzed in Discovery Studio and Pymol software [51]. Validation of docking protocol was done by redocking of the co-crystallized ligand, N3 (N-[(5-METHYLISOXAZOL-3-YL)CARBONYL]ALANYL-LVALYL-N 1 -((1R,2Z)-4-(BENZYLOXY)-4-OXO-1-\{[(3R)-2-OXOPYRROLIDIN-3-

YL]METHYL\}BUT-2-ENYL)-L-LEUCINAMIDE) over 3CLpro.

\subsection{Pharmacokinetics, Drug-like, Lead-like and ADMET Evaluations}

Pubchem database [51] was utilized to obtain the canonical smiles of the various selected ligands. The pharmacokinetics of the ligands having the best poses were predicted using the online pkCSM software [52]. The major parameters associated with ADME properties such as the Lipinski's rule of five [Molecular weight, (MW) <500Da; octanol-water partition coefficient (log P) $<5$, HBond donor (HBD) $\leq 5$, HBond 
acceptor (HBA) $\leq 10$ ]; Caco-2 permeability, topological surface area (TPSA) and water solubility (LogS) of the compounds were considered. Two sets of criteria were employed for assessing the suitability of ligands for lead discovery: "drug-like" and "lead-like". The drug-like hits were based on the Muegge (Bayer) criteria [53] for which $200 \leq \mathrm{MW} \leq 600,-2 \leq \operatorname{LogP} \leq 5$, TPSA $\leq 150, \mathrm{HBD} \leq 5, \mathrm{HBA} \leq 10$, and Rotatablebond, RotB $\leq 15$. Whereas the lead-like criteria were $\log \mathrm{P}<3, \mathrm{MW}<300, \mathrm{HBD} \leq 3, \mathrm{HBA} \leq 3$, and $\mathrm{Rot} \mathrm{B} \leq 3$. Using the pkCSM software, the hepatotoxicity, Minnow toxicity (Mtox), and T.Pyriformis toxicity (TPtox) were also considered.

\section{Results and Discussion}

A total of 38 compounds (Figure1-3) from T. foenum-graecum, N. sativa and A. muricata were screened in this study for their SARS-COV-2 main protease, 3CLpro inhibitory potentials. 3CLpro inhibition was also studied for experimental and investigational drugs being considered for the treatment of COVID-19 chloroquine, hydroxychloroquine, indinavir, remdesivir and ritonavir (Figure 4). The amino acids: THR25, THR26, HIS41, MET49, PHE140, LEU141, AASN142, GLY143, SER144, CYS 145, HIS163, HIS164, MET145 GLU166 and PRO168 were revealed to be significant binding site residues which could come into Hydrogen bond, electrostatic, and Hydrophobic interactions by the active site identification protocol for 3CL/Mpro using the online PLIP server [45]. Among the 38 ligands screened, compounds from T. foenumgraecum showed stronger inhibitions of 3CLpro/Mpro compared to those N. sativa and A. muricata. The docking result obtained in this study as presented in Table 1 showed that SARS-COV-2 main protease, 3CL/Mpro inhibition occurred with binding affinities ranging between $-5.3 \mathrm{kcal} / \mathrm{mol}$ to $-8.1 \mathrm{kcal} / \mathrm{mol}$ indicating significant binding interactions at the active site binding pocket. These interactions were stabilized through the formation of hydrogen bonds, electrostatic and hydrophobic interactions (Tables 1 and 3 ). Another important interaction observed which mostly involve the transfer of charges was pi-interactions such as Pi-Pi interaction, Pi-Alkyl interaction, Pi-Sulfur interaction, Pi- Sigma, and Pi-Pi stacking. These Pi interactions helped imbed the ligands in the active/binding site of the 3CLpro. Drug-like characteristics prediction using the pKCSM server [52] however demonstrated that only 8 of the ligands screened were actually drug-like while none was lead-like (Table 2). The drug-like ligands were apigenin, kaempferol, luteolin, dithymoquinone, naringenin, quercetin, nornuciferine, and nigellidine. Apigenin, a common potent dietary flavonoid with antiviral and antitumor activity showed a negative binding affinity of $-6.8 \mathrm{kcal} / \mathrm{mol}$ and four conventional hydrogen bonds with LEU141, SER144, HIS163, and GLU166 according to the docking result obtained (Tables 1and 3). The stable binding interaction could further be linked to the Pi-sulfur interaction of apigenin ring with CYS145 in conjunction with the Pi-Alkyl interaction established with MET49 of the protease binding site. This is in contrast to chloroquine which hydrogen-bonded with LEU141 and HIS164 and in electrostatic interaction with GLU166 (Table 1). Kaempferol, a biologically active flavonoid with antiviral, anti-inflammatory, antioxidant, antimicrobial and anticancer activities exhibited 
stable binding with a binding affinity of $-7.1 \mathrm{kcal} / \mathrm{mol}$. This is attributed to its four conventional hydrogen bonds with GLU166, ASP187, GLU189, and SER144 together with electrostatic interaction with HIS 41. The stability of binding is further sustained by Pi-Stacked and Pi-alkyl hydrophobic interactions with HIS41 and MET49 respectively. The presence of Pi-Sulfur interactions with CYS145 and MET165 further enhanced binding at the enzyme's binding site. Luteolin, used traditionally in herbal medicines for treating inflammatory disorders, hypertension, and cancer demonstrated five conventional hydrogen bonding interactions with LEU141, GLY143, SER144, GLU166 and ARG188. Two different Pi-Alkyl hydrophobobic interactions were additionally noted with MET165 and CYS145 which aided conformational stability of kaempferol at the 3CLpro receptor binding site. As noted for Apigenin and Kaempferol, these were noteworthy interactions over 3CLpro. The Pi-Alkyl typed hydrophobic interactions of dithymoquinone with HIS41, CYS145, MET165 and LEU167 (Tables 1 and 3) from the docking results were responsible for its inhibitory potential against the SARS-COV-2 main protease insilico. These interactions, majorly involving charge transfer helped intercalate the ligand at the protease binding site. Its binding affinity of $6.2 \mathrm{kcal} / \mathrm{mol}$ is greater compared to those of ritonavir, indinavir and remdesivir: $-7.7 \mathrm{kcal} / \mathrm{mol},-7.6 \mathrm{kcal} / \mathrm{mol}$ and $-6.8 \mathrm{kcal} / \mathrm{mol}$ - respectively obtained in this study (Table 1). The Pi-alkyl hydrophobic interactions of naringenin, an anti-obesity, anti-diabetic, anti-dyslipidemic, and antifibrotic flavonoid from T. foenumgraecum with MET49 and CYS145 in addition to Hbond interactions with LEU141, CYS145, Ser144 and HIS163 contributed to the its stable conformational binding energy of $-6.9 \mathrm{kcal} / \mathrm{mol}$. This is similar to the result obtained for quercetin but a Pi-sulfur hydrophobic interaction with CYS145 along with an additional Hbond with GLY143 were attributed to the favourable binding of quercetin at the receptor's binding site. Table 3 further revealed that the Pi-Cation interaction of nornuciferine from A. muricata with HIS41 was balanced by a Pi-donor Hydrogen bonding of the nornuciferine ring with CYS145. This was in addition to two conventional hydrogen bonding it formed with LEU141 and HIS164 of the receptor active site. Pi-Sigma and Pi-Sulfur interactions with HIS41 and MET49 respectively also contributed to the stability of binding at the binding site. Another compound from N. sativa, besides dithymoquinone, Nigellidine, exhibited significant binding interactions through its four Hbonds with THR26, GLY143, SER144 and CYS145. Further hydrophobic interactions with HIS41, MET49, HIS163 and HIS172 along with electrostatic interaction with HIS41 stabilized the binding of nigellidine at the 3CLpro None of the drug-like compounds was lead-like having not satisfied the limits for lead-like characteristics: $\log P<3, \operatorname{MW}<300, \operatorname{HBD} \leq 3$, $\mathrm{HBA} \leq 3$, and RotB $\leq 3$ (Table 2). However, they showed comparatively favourable predicted insilico absorption characteristics as indicated by the $\log S$ (water solubility) and Caco-2 permeability values to the five experimental and investigational drugs utilized in this study (Table 2). Caco-2 permeability (Caco-2 cell line composed of human epithelial colorectal adenocarcinoma cells is an in vitro model of the human mucosa) is widely used to predict the absorption of orally administered drugs with high Caco-2 permeability being $>0.9$ [ ]. The predictive results obtained in this study showed Caco-2 permeability of quercetin to be 
very poor (-0.229) as also was the case with kaempferol (0.032) and luteolin (0.0916). The other ligands in contrast showed high Caco-2 permeability varying from 1.007 for apigenin to 1.47 for nornuciferine, a result lower than those of hydroxychloroquine (1.543) and chloroquine (1.624) but greater than those of indinavir (0.823), ritonavir (0.377) and remdesivir (0.635). These suggest good human mucosa absorption of these drug-like compounds. T. pyriformis is a protozoa bacteria whose toxicity is oftentimes used as a toxic endpoint [52]. The predicted results for T. pyriformis toxicity of the drug-like ligands varied from 0.288 for quercetin to 1.437 for nigelidine (Table 2). Also considered in this study are the predicted hepatotoxicity and Minnow toxicity (LC50) - representing the concentration of molecules to cause $50 \%$ death of the Flathead Minnows [52]. The drug-like phytochemicals lacked hepatotoxicities while naringenin had the lowest Minnows toxicity (0.039).

Docking of the N3 co-crystallized ligand showed interactions of the terminal ends of the N3 co-crystallized ligand through Hbonds with PHE140, GLU166, GLY143, CYS145, and LEU167 (Figure 5). Hydrophobic Alkyl and Pi-Alkyl interactions were also observed with MET165, MET49, and PRO168. This correlated favorably the interactions of the 8 drug-like ligands proposed as inhibitors of SARS-COV-2 main protease, 3CLpro in this study.

Results obtained in this study were different in several ways to other docking reports recently published. Zhang et al. [54] used a library consisting of 13 antiviral compounds which included quercetin and kaempferol from 26 Chinese traditional herbs in a docking study with 3CLpro, PLpro, and Spike proteins. Kaempferol and quercetin were reported to inhibit 3CLpro with binding affinities of $-6.01 \mathrm{kcal} / \mathrm{mol}$ and $6.25 \mathrm{kcal} / \mathrm{mol}$ respectively. Bouchentouf and Missoum [55] reported that nigellidine from N. sativa also inhibited SARS-COV-2 but reported only one Hbond interaction with HIS163. The binding energy of the best pose in the docking protocol of $\mathrm{N} 3$ in this study $(-6.5 \mathrm{kcal} / \mathrm{mol})$ was also different from that obtained ($8.1 \mathrm{kcal} / \mathrm{mol}$ ) in another study [56]. Differences in conformational search algorithms coupled with intrinsic randomness of conformational search could be responsible for such small differences which were not unexpected though. The predictive results of this study and other recently reported docking studies could be supported by further experimental in vivo studies using SARS-COV-2 animal models for use against SARSCOV-2.

\section{Conclusion}

The medicinal properties of traditional plants would be important considerations in the search for therapeutic solutions against lots of emerging diseases. Several approaches are involved in this among which bioinformatics offer a viable tool for screening many potential options. The molecular docking and ADMET evaluations of ligands from N. sativa, T. foenum-graecum and A. muricata considered in this study showed that 8 drug-like molecules from these medicinal plants were potent inhibitors of 3CLpro and lacked 
hepatotoxicity effects while none was lead-like. Insilico results of this study further suggested that drug repurposing candidates, remdesivir, indinavir,hydroxychloroquine, chloroquine and ritonavir,exhibited various interactions with 3CLpro. Hence, further in vitro and in vivo studies are proposed.

\section{Conflicts of Interest}

None

\section{References}

1. World Health Organization (2020, May 26). Retrieved from https://covid19.who.int/?gclid=EAIaIQobChMIhvLH2NfR6QIViIxRCh0QtQJPEAAYASAAEgI53fD_BwE

2. Vellingiri, Balachandar, et al. "COVID-19: A promising cure for the global panic." Science of the Total Environment (2020): 138277.

3. Dhruv K., Vaishali C., Sibi R., \& Brijesh R. (2020, March, 23). In silico Identification of Potent COVID19 Main Protease Inhibitors from FDA Approved Antiviral Compounds and Active Phytochemicals through Molecular Docking: A Drug Repurposing Approach.http://doi:10.20944/preprints202003.0349.v1i:1kk0.20

4. Ullah, Md Asad, et al. "Pathogenesis, Diagnosis and Possible Therapeutic Options for COVID-19." (2020).

5. Bzowka M. et al.. 'Molecular Dynamics Simulations Indicate the COVID-19 Mpro Is Not a Viable Target for Small-Molecule Inhibitors Design’’ preprint doi: https://doi.org/10.1101/2020.02.27.968008.

6. Bagherzadeh K. et al. 'In silico Repositioning for Dual Inhibitor Discovery of SARS-CoV-2 (COVID-19) 3C-like Protease and Papain-like Peptidase. Preprint doi:10.20944/preprints202003.0349.v1i:

7. $\mathrm{Wu}$, Canrong, et al. "Analysis of therapeutic targets for SARS-CoV-2 and discovery of potential drugs by computational methods." Acta Pharmaceutica Sinica B (2020).

8. Gore, Mohini, and Umesh B. Jagtap, eds. Computational drug discovery and design. Humana Press, 2018.

9. Ahmad, A., Husain, A., Mujeeb, M., Khan, S. A., Najmi, A. K., Siddique, N. A., ... \& Anwar, F. (2013). A review on therapeutic potential of Nigella sativa: A miracle herb. Asian Pacific journal of tropical biomedicine, 3(5), 337-352. 9. Ahmad A et al. A review on therapeutic potential of Nigella sativa: A miracle herb. Asian Pac J Trop Biomed 3.5 (2013):337-352.

10.Kalus U et al. Effect of Nigella sativa (black seed) on subjective feeling in patients with allergic diseases. Phytother Res 17.10 (2003): 1209-14 
11. Isik $\mathrm{H}$ et al. Potential adjuvant effects of Nigella sativa seeds to improve specifc immunotherapy in allergic rhinitis patients. Med Princ Pract 19 (2010):206-211

12. Nikakhlagh $\mathrm{S}$ et al. Herbal treatment of allergic rhinitis: the use of Nigella sativa. American Journal of Otolaryngology-Head and Neck Medicine Surgery 32 (2011):402-407.

13. MA, Alghamdi MS. Anticancer activity of Nigella sativa (blackseed) - a review. The American Journal of Chinese Medicine 39.6 (2011):1075-1091.

14. Woo CC et al. Thymoquinone: Potential cure for inflammatory disorders and cancer. Biochemical Pharmacology 83 (2012): 443-451.

15. Kaleem M et al. Biochemical effects of Nigella sativa L seeds in diabetic rats. Indian J Exp Biol. 44.9 (2006):745-8.

16. Najmi A et al. Effect of Nigella sativa oil on various clinical and biochemical parameters of insulin resistance syndrome. Int J Diabetes Dev Ctries 28.1 (2008):11-4.

17. Meddah B et al. Nigella sativa inhibits intestinal glucose absorption and improves glucose tolerance in rats. J Ethnopharmacol. 121.3 (2009):419-24

18. Bamosa AO et al. Effect of Nigella sativa seed on the glycemic control of patients with type 2 diabetes mellitus. Indian J Physiol Pharmacol 54.4 (2010):344-54.

19. Fararh KM, et al. Thymoquinone enhances the activities of enzymes related to energy metabolism in peripheral leucocytes of diabetic rats. Res Vet Sci. 88.3 (2010):400-4.

20. El-Tahir KEH, et al. The cardiovascular actions of the volatile oil of the black seed (Nigella sativa) in rats: elucidation of the mechanism of action. Gen Pharmac 24: 5 (1993): 1123-1131.

21. Duke, James A. Handbook of phytochemical constituents of GRAS herbs and other economic plants. Boca Raton, FL. CRC Press (1992).

22. Raju $\mathbf{J}$ et al. Trigonella foenum graecum (fenugreek) seed powder improves glucose homeostasis in alloxan diabetic rat tissues by reversing the altered glycolytic, gluconeogenic and lipogenic enzymes. Mol Cell Biochem 224.1-2 (2001): 45-51

23. Vats V, et al. Evaluation of anti-hyperglycemic and hypoglycemic effect of Trigonella foenum-graecum Linn, Ocimum sanctum Linn and Pterocarpus marsupium Linn in normal and alloxanized diabetic rats. J Ethnopharmacol 79.1 (2002): 95-100 
24. Pandian RS, et al. Gastroprotective effect of fenugreek seeds (Trigonella foenum-graecum) on experimental gastric ulcer in rats. J Ethnopharmacol 81.3 (2002): 393-397.

25. Boban PT, et al. Dietary mucilage promotes regression of atheromatous lesions in hypercholesterolemic rabbits. Phytother Res 23.5 (2008): 725-730.

26. Belguith-Hadriche $\mathrm{O}$, et al. Comparative study on hypocholesterolemic and antioxidant activities of various extracts of fenugreek seeds, Food Chemistry 138 (2013) 1448-1453.

27. Javan M et al. Antinociceptive effects of Trigonella foenum-graecum leaves extract. J Ethnopharmacol 58.2 (1997): 125-129.

28. Ahmadiani A et al. Anti-inflammatory and antipyretic effects of Trigonella foenum-graecum leaves extract in the rat. J Ethnopharmacol 75.2-3 (2001): 283-286.

29. Bin-Hafeez B et al. Immunomodulatory effects of fenugreek (Trigonella foenum graecum L.) extract in mice. Int Immunopharmacol 3.2 (2003): 257-265

30. Bukhari, S.B., Muhammad, I.B., Shahabuddin, M., 2008. Antioxidant activity from the extract of fenugreek seeds. Pak. J. Anal. Environ. Chem. 9 (2), 78-83

31. Sowmya P, Rajyalakshmi P. Hypocholesterolemic effect of germinated fenugreek seeds in human subjects. Plant Foods Hum Nutr 53.4 (1999): 359-365.

32. Blank, Imre, et al. "The principal flavor components of fenugreek (Trigonella foenum-graecum L.)." 1997. 12-28.Mathern, Jocelyn R., et al. "Effect of fenugreek fiber on satiety, blood glucose and insulin response and energy intake in obese subjects." Phytotherapy research 23.11 (2009): 1543-1548.

33. Mathern, Jocelyn R., et al. "Effect of fenugreek fiber on satiety, blood glucose and insulin response and energy intake in obese subjects." Phytotherapy research 23.11 (2009): 1543-1548.

34. Moghadamtousi, Soheil Zorofchian, et al. "Annona muricata (Annonaceae): a review of its traditional uses, isolated acetogenins and biological activities." International journal of molecular sciences 16.7 (2015): $15625-15658$.

35. Chan, P., R. Ah, and K. Mh. "Anti-arthritic activities of Annona muricata L. leaves extract on complete Freund's adjuvant (CFA)-induced arthritis in rats." Planta Medica 76.12 (2010): P166.

36. Astirin, Okid Parama, et al. "Annonaa muricata linn leaf induce apoptosis in cancer cause virus." Journal of Cancer Therapy 4.07 (2013): 1244. 
37. Gavamukulya, Yahaya, et al. "Phytochemical screening, anti-oxidant activity and in vitro anticancer potential of ethanolic and water leaves extracts of Annona muricata (Graviola)." Asian Pacific journal of tropical medicine 7 (2014): S355-S363.

38. George, V. Cijo, et al. "Quantitative assessment of the relative antineoplastic potential of the n-butanolic leaf extract of Annona muricata Linn. in normal and immortalized human cell lines." Asian Pacific Journal of Cancer Prevention 13.2 (2012): 699-704.

39. Osorio, Edison, et al. "Antiprotozoal and cytotoxic activities in vitro of Colombian Annonaceae." Journal of ethnopharmacology 111.3 (2007): 630-635.

40. Bories, Christian, et al. "Antiparasitic activity of Annona muricata and Annona cherimolia seeds." Planta medica 57.05 (1991): 434-436.

41. Ferreira, L. E., et al. "In vitro anthelmintic activity of aqueous leaf extract of Annona muricata L.(Annonaceae) against Haemonchus contortus from sheep." Experimental parasitology 134.3 (2013): 327 332.

42. Wani, Sajad Ahmad, and Pradyuman Kumar. "Fenugreek: A review on its nutraceutical properties and utilization in various food products." Journal of the Saudi Society of Agricultural Sciences 17.2 (2018): 97106.Jaramillo, M. C., et al. "Cytotoxicity and antileishmanial activity of Annona muricata pericarp." Fitoterapia 71.2 (2000): 183-186.

43. Molla et al. A review on antiviral effects of Nigella sativa L. http://pharmacologyonline.silae.it (2019).

44. Bank, Protein Data. "Protein data bank." Nature New Biol 233 (1971): 223.

45. Salentin, Sebastian, et al. "PLIP: fully automated protein-ligand interaction profiler." Nucleic acids research 43.W1 (2015): W443-W447.

46. Studio, Discovery. "Discovery Studio." Accelrys [2.1] (2008).

47. Wolf, L. K. "PyRx." C\&EN 87 (2009): 31.

48. Kim, Sunghwan, et al. "PubChem substance and compound databases." Nucleic acids research 44.D1 (2016): D1202-D1213.

49. Wishart, David S., et al. "DrugBank 5.0: a major update to the DrugBank database for 2018." Nucleic acids research 46.D1 (2018): D1074-D1082. 
50. Trott, Oleg, and Arthur J. Olson. "AutoDock Vina: improving the speed and accuracy of docking with a new scoring function, efficient optimization, and multithreading." Journal of computational chemistry 31.2 (2010): 455-461.

51. DeLano, Warren Lyford. "PyMOL." (2002): 700.

52. Pires, Douglas EV, Tom L. Blundell, and David B. Ascher. "pkCSM: predicting small-molecule pharmacokinetic and toxicity properties using graph-based signatures." Journal of medicinal chemistry 58.9 (2015): 4066-4072.

53. Muegge, Ingo, Sarah L. Heald, and David Brittelli. "Simple selection criteria for drug-like chemical matter." Journal of medicinal chemistry 44.12 (2001): 1841-1846.

54. Zhang, Deng-hai, et al. "In silico screening of Chinese herbal medicines with the potential to directly inhibit 2019 novel coronavirus." Journal of integrative medicine 18.2 (2020): 152-158.

55. Bouchentouf Salim and Missoum Noureddine: Identification of Compounds from Nigella Sativa as New Potential Inhibitors of 2019 Novel Coronasvirus (COVID-19): Molecular Docking Study. Preprint doi:10.20944/preprints202004.0079.v1.56

56. Talluri Sekhar. Virtual Screening Based Prediction of Potential Drugs for COVID-19. Preprint. Doi:10.20944/preprints202002.0418.v2 
Nigelllicine<smiles>Cc1cc2n3n(c(C(=O)O)c-2c(=O)c1)CCCC3</smiles>

Dithymoquinone

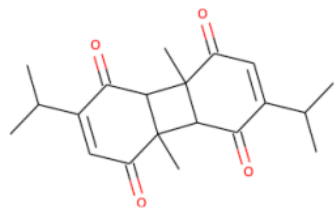

Pinene

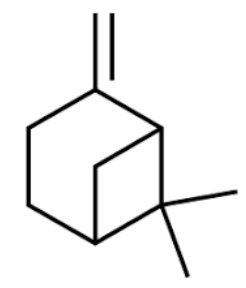

Alpha-hederin

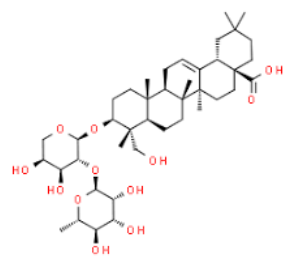

Isoquinone<smiles>c1ccc2cnccc2c1</smiles>

Thymoquinone

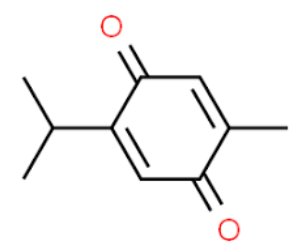

alpha-terpeneol<smiles>CC1=CCC(C(C)(C)O)CC1</smiles>

Longifolene
Anethole<smiles>C/C=C/c1ccc(OC)cc1</smiles>

Nigellidine

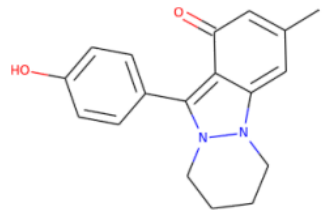

Carvacrol<smiles>Cc1ccc(C(C)C)cc1O</smiles>

p-cymene<smiles>Cc1ccc(C(C)C)cc1</smiles>

Thymol<smiles>Cc1ccc(C(C)C)c(O)c1</smiles>
beta-sitosterol

Rutin

Stigmasterol

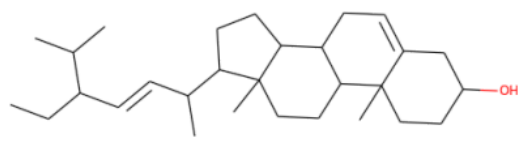

Figure 1: Compounds from Nigella sativa

beta-sitosterol

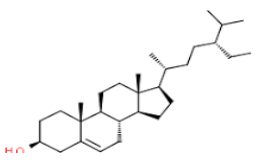

Muricatacin

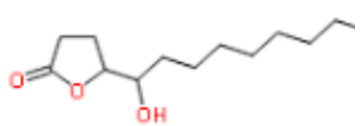

Stigmasterol

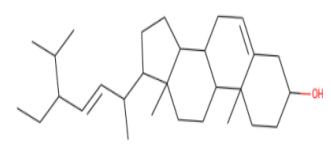

Nornuciferine

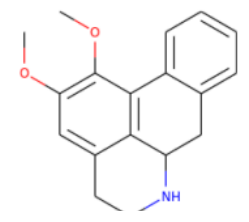

Procyanidin

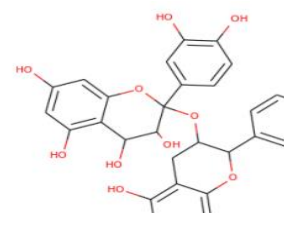

Quercitrin

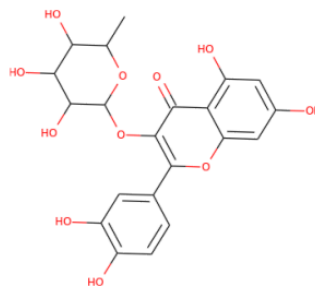

Annonaine<smiles>C[C@]12Cc3ccccc3-c3c4c(cc(c31)CCN2)OCO4</smiles>

Kaempferol
Assimilobine<smiles>COc1c(O)cc2c3c1-c1ccccc1C[C@H]3NCC2</smiles>

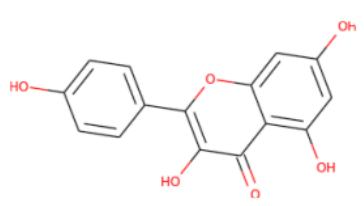




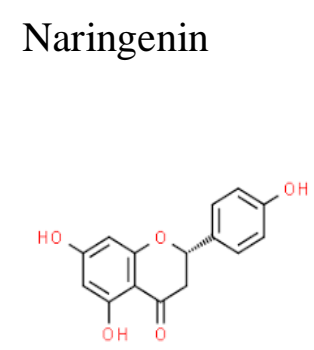

Apigenin

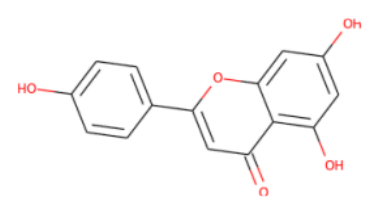

Quercetin

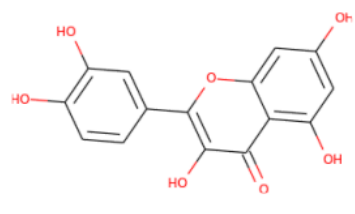

Tricin<smiles>COc1cc(-c2cc(=O)c3c(O)cc(O)cc3o2)cc(OC)c1O</smiles>

Vitexin

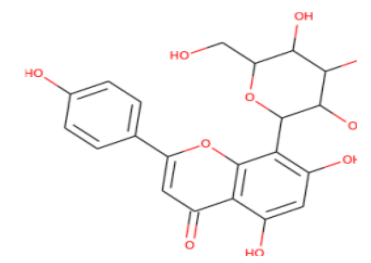

beta-sitosterol

Carpaine

Diosgenin

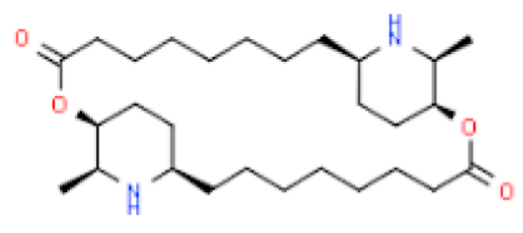

Fenugreekine
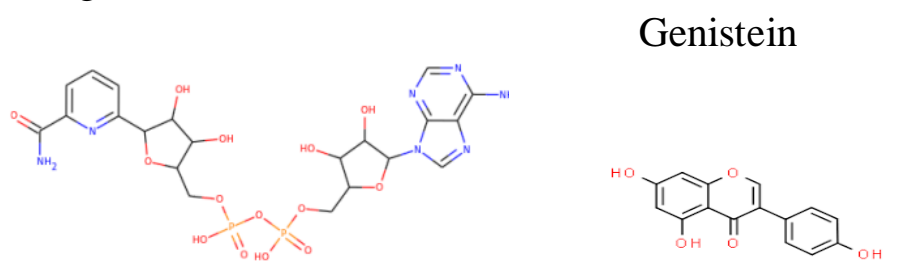

Gentianine

Gigogenin

Luteolin

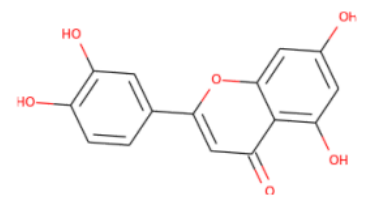

Quercitrin

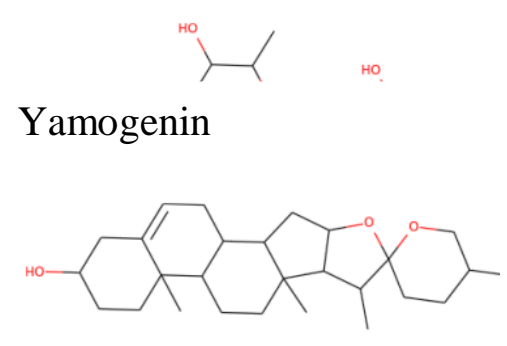

Kaempferol

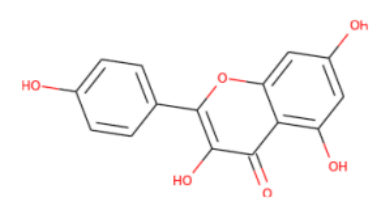

Rutin

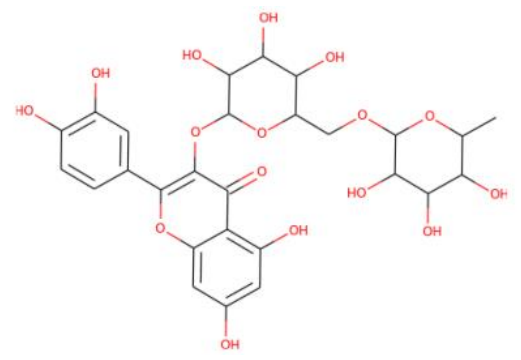

Neotogogenin

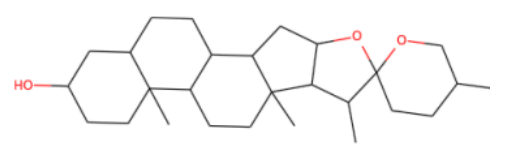

Stigmasterol

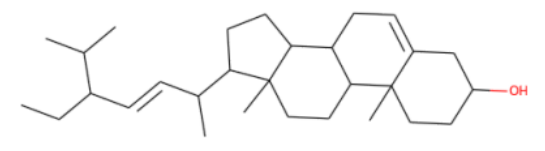

Yuccagenin

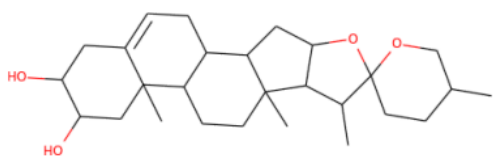


Chloroquine

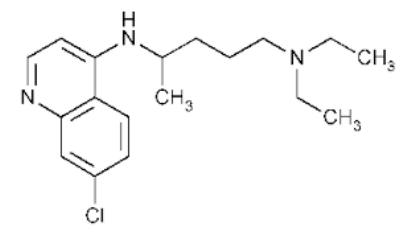

Indinavir

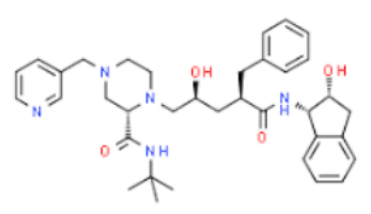

Hydroxychloroquine

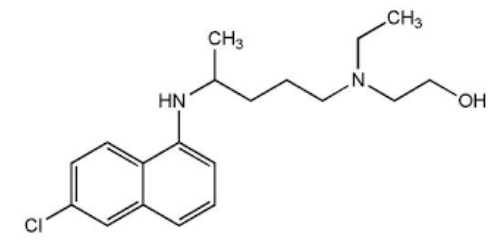

Ritonavir

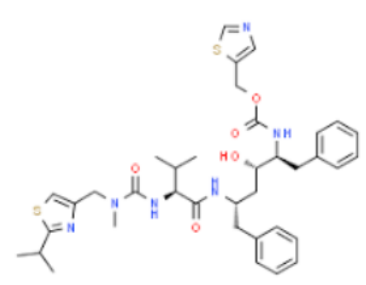

Remdesivir

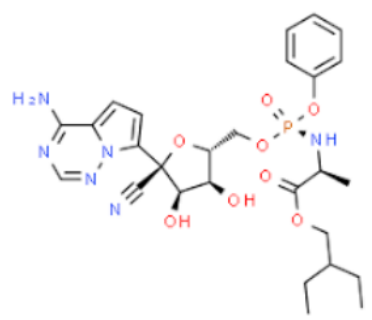

Figure 4: Experimental and Investigational Drugs 
Table 1: Ligands Interactions Over SARS-COV-2 Main protease, 3CLpro/Mpro

\begin{tabular}{|c|c|c|c|c|}
\hline \multirow[t]{2}{*}{ Compound } & \multicolumn{4}{|l|}{ Binding } \\
\hline & $\begin{array}{l}\text { Affinity } \\
\text { (Kcal/mol) }\end{array}$ & HBond & Hydrophobic & Electrostatic \\
\hline Apigenin & -6.8 & LEU141-SER144-HIS163-GLU166 & MET49 & - \\
\hline Gentianine & -5.3 & GLY143-SER144-CYS145 & HIS163-MET165 & - \\
\hline Gitogenin & -8.1 & - & HIS41-MET49-CYS145 & - \\
\hline Kaempferol & -7.1 & SER144-GLU166-GLN189-ASP187 & HIS41-MET49 & - \\
\hline Luteolin & -7.1 & LEU141-SER144-GLY143-GLU166-ARG188 & CYS145-MET165 & - \\
\hline Neotigogenin & -7.3 & HIS163 & HIS41-MET49-HIS163 & - \\
\hline Procyanidin & -7.7 & PHE140-HIS163 & HIS41-MET49-CYS145 & GLU166 \\
\hline Quarcitrin & -7.2 & THR26-PHE140-GLU166 & LEU141-CYS145 & - \\
\hline Rutin & -7.7 & HIS41-PHE140-GLY143-GLU166-ASN142 & CYS145 & - \\
\hline Yamogenin & -7.5 & THR26 & HIS41-CYS145-MET165-PRO168 & - \\
\hline Yuccagenin & -7.8 & - & HIS41-CYS145 & \\
\hline Dimothymoquinone & -6.2 & - & $\begin{array}{l}\text { HIS41-CYS145-MET165- } \\
\text { LEU167 }\end{array}$ & - \\
\hline Stigmasterol & -7.0 & THR26 & $\begin{array}{l}\text { HIS41-CYS145-MET165- } \\
\text { PRO168 }\end{array}$ & - \\
\hline Naringenin & -6.9 & LEU141-SER144-CYS145-HIS163 & MET49-CYS145 & - \\
\hline Quarcetin & -7.2 & LEU141-SER144-CYS145-HIS163 & - & - \\
\hline Nigellidine & -7.7 & THR26-GLY143-SER144-CYS145 & HIS41 & \\
\hline Vitexin & -7.5 & LEU141-SER144-HIS164 & - & \\
\hline Fenugreekine & -7.9 & $\begin{array}{l}\text { THR26-LEU141-GLY143-CYS145-HIS163- } \\
\text { GLU166-GLN189-HIS172 }\end{array}$ & - & - \\
\hline Nornuciferine & -6.6 & LEU141-CYS145-HIS164 & HIS41 & HIS41 \\
\hline Indinavir & -7.6 & THR26-ASN142-HIS164-GLN189 & HIS41-CYS145 & - \\
\hline Ritonavir & -7.7 & THR26-HIS41-GLU166-GLN189 & HIS41-MET165-PRO168 & HIS41-GLU166 \\
\hline Remdesivir & -6.8 & ASN142-GLY143-HIS164 & CYS145 & HIS41 \\
\hline Hydroxychl-oroquine & -5.9 & THR26-ASN142-SER144 & HIS41 & - \\
\hline Chloroquine & -5.6 & LEU141-HIS164 & - & GLU166 \\
\hline
\end{tabular}


Table 2: Predicted Pharmacokinetics of ligands

\begin{tabular}{|c|c|c|c|c|c|c|c|c|c|c|c|c|c|}
\hline Compound & MW & LogP & RotB & HBA & HBD & TPSA & $\log S$ & Caco2 & Hepatotoxicity & T.Ptox & M.Ttox & Drug-like & Lead-like \\
\hline Apigenin & 270.24 & 2.577 & 1 & 5 & 3 & 112.519 & -3.329 & 1.007 & No & 0.38 & 2.432 & Yes & No \\
\hline Gentianine & 175.187 & 1.438 & 1 & 3 & 0 & 76.055 & -1.27 & -1739 & Yes & 0.249 & 1.468 & No & No \\
\hline Gitogenin & 432.645 & 4.765 & 0 & 4 & 2 & 76.055 & -5.01 & 1.272 & No & 0.339 & 0.821 & No & No \\
\hline Kaempferol & 286.239 & 2.282 & 1 & 6 & 4 & 117.313 & -3.04 & 0.032 & No & 0.312 & 2.885 & Yes & No \\
\hline Luteolin & 286.239 & 2.282 & 1 & 6 & 4 & 117.313 & -3.094 & 0.096 & No & 0.326 & 3.169 & Yes & No \\
\hline Neotigogenin & 416.646 & 5.794 & 0 & 3 & 1 & 183.214 & -5.485 & 1.301 & No & 0.375 & 0.281 & No & No \\
\hline Procyanidin & 594.525 & 2.7327 & 4 & 13 & 10 & 242.064 & -2.892 & 0.131 & No & 0.285 & 10.607 & No & No \\
\hline Quercitrin & 448.38 & 0.4887 & 3 & 11 & 7 & 179.107 & -2.903 & 0.048 & No & 0.285 & 4.954 & No & No \\
\hline Rutin & 610.521 & -1.6871 & 6 & 16 & 10 & 240.901 & -2.892 & -0.949 & No & 0.285 & 7.677 & No & No \\
\hline Yamogenin & 414.63 & 5.7139 & 0 & 3 & 1 & 182.524 & -5.539 & 1.293 & No & 0.399 & 0.247 & No & No \\
\hline Yuccagenin & 430.629 & 4.6847 & 0 & 4 & 2 & 187.319 & -5.096 & 1.264 & No & 0.351 & 0.787 & No & No \\
\hline Dithymoquinone & 328.408 & 2.7134 & 2 & 4 & 0 & 141.923 & -3.654 & 1.367 & No & 0.445 & 1.323 & Yes & No \\
\hline Stigmasterol & 412.702 & 7.8008 & 5 & 1 & 1 & 186.349 & -6.682 & 1.213 & No & 0.433 & -1.675 & No & No \\
\hline Naringenin & 272.256 & 2.510 & 1 & 5 & 3 & 114.235 & -3.224 & 1.029 & No & 0.369 & 2.136 & Yes & No \\
\hline Quercetin & 302.238 & 1.988 & 1 & 7 & 5 & 122.108 & -2.925 & -0.229 & No & 0.288 & 3.721 & Yes & No \\
\hline Vitexin & 432.381 & 0.0917 & 3 & 10 & 7 & 173.994 & -2.845 & -0.956 & No & 0.285 & 4.897 & No & No \\
\hline Nornuciferine & 281.355 & 3.1137 & 2 & 3 & 1 & 124.443 & -3.597 & 1.47 & Yes & 0.282 & 0.039 & Yes & No \\
\hline Fenugreekine & 663.43 & -2.3659 & 11 & 18 & 8 & 245.744 & -2.891 & -0.711 & No & 0.285 & 10.164 & No & No \\
\hline Nigellidine & 294.354 & 3.22942 & 1 & 4 & 1 & 128.116 & -3.651 & 1.304 & Yes & 1.437 & 1.17 & Yes & No \\
\hline Indinavir & 613.803 & 2.8669 & 11 & 7 & 4 & 266.218 & -3.611 & 0.823 & Yes & 0.285 & 5.061 & & \\
\hline Ritonavir & 720.962 & 5.9052 & 17 & 9 & 4 & 302.058 & -3.358 & 0.377 & Yes & 0.285 & 1.787 & & \\
\hline Remdesivir & 602.585 & 2.31218 & 13 & 13 & 4 & 242.488 & -3.07 & 0.635 & Yes & 0.285 & 0.291 & & \\
\hline Hydroxychloroquine & 335.879 & 3.783 & 9 & 4 & 2 & 143.024 & -3.627 & 1.543 & Yes & 1.061 & 1.325 & & \\
\hline Chloroquine & 319.88 & 4.8106 & 8 & 3 & 1 & 138.230 & -4.249 & 1.624 & Yes & 1.558 & 0.747 & & \\
\hline
\end{tabular}


Table 3: Interactions of Drug-like Compounds

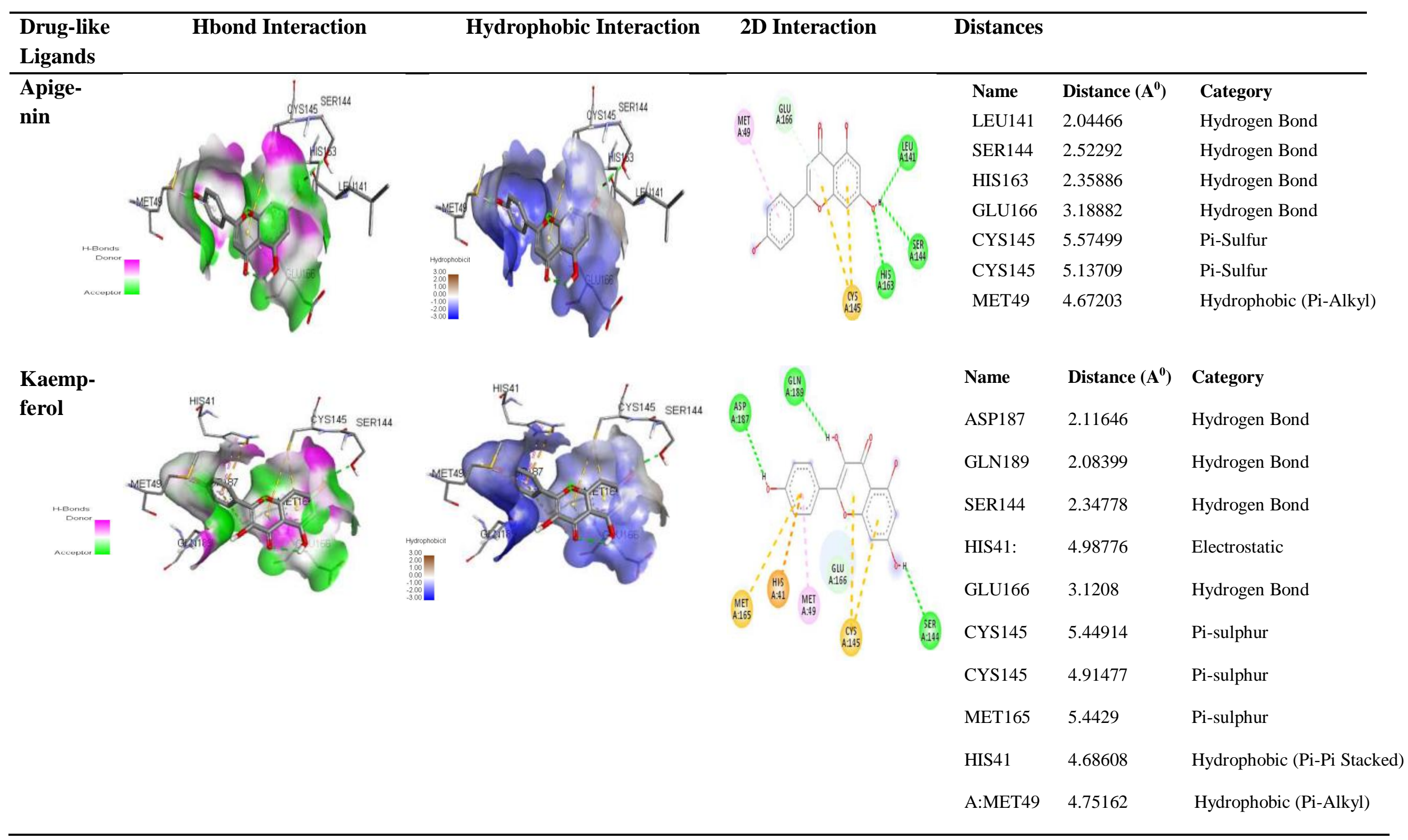




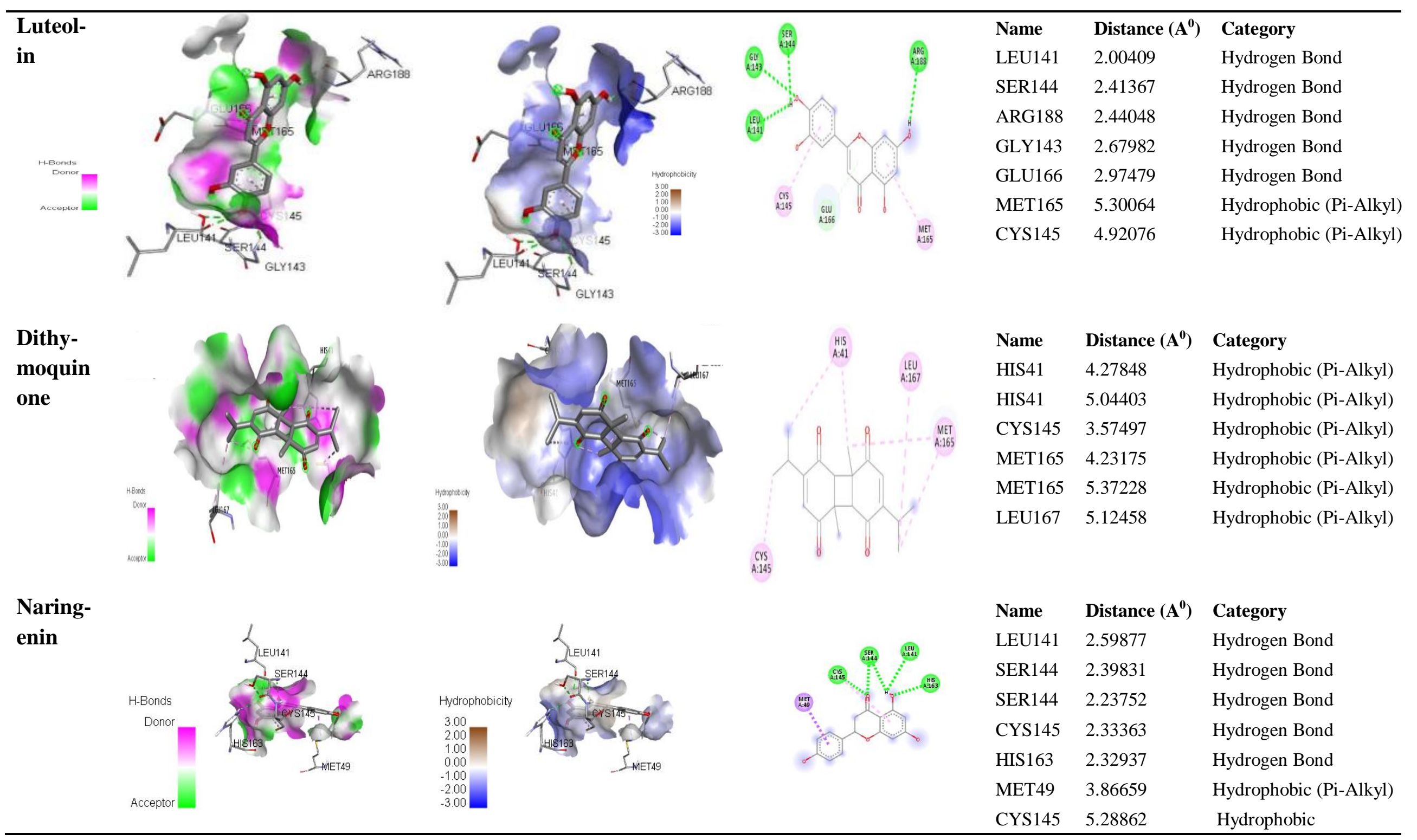




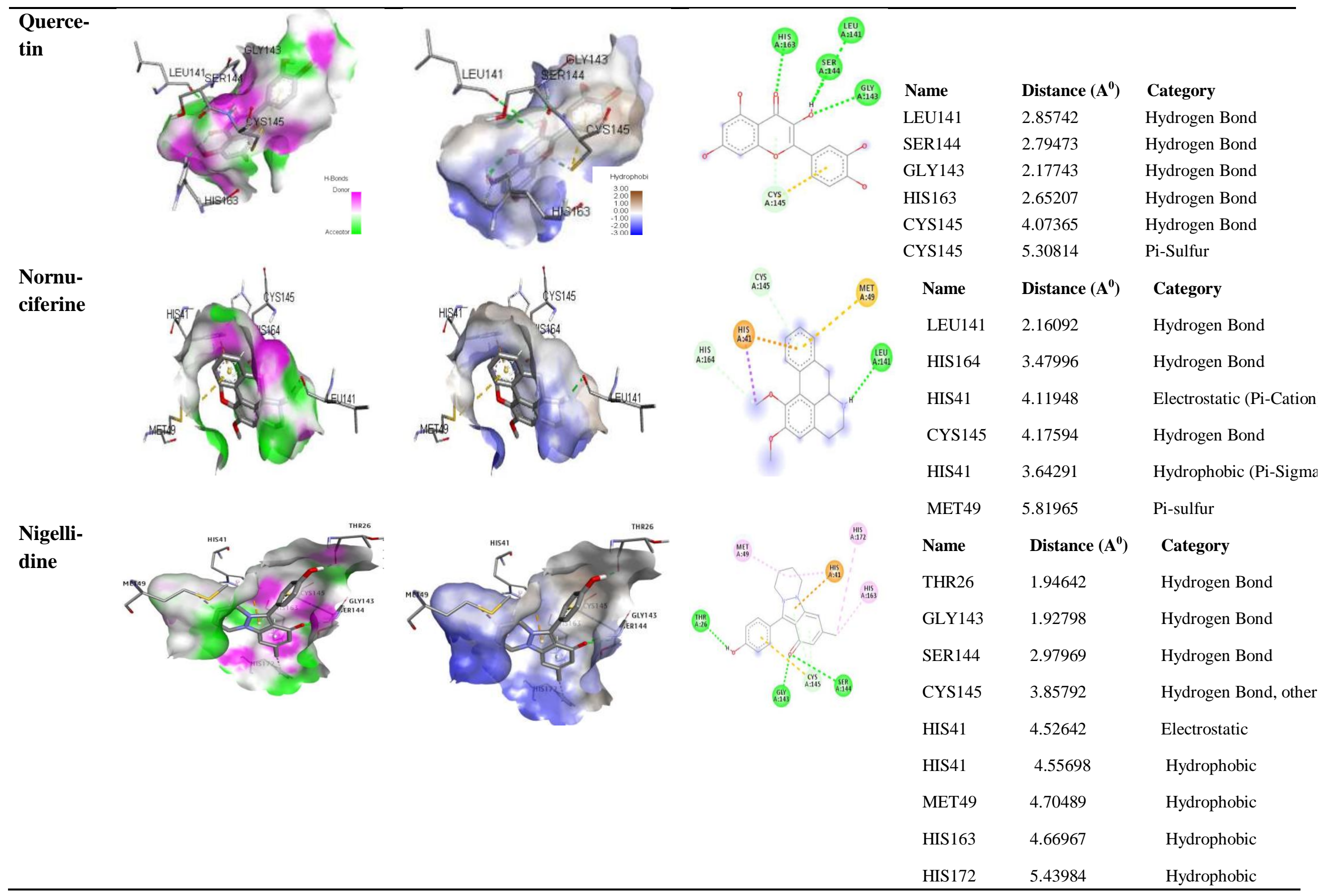




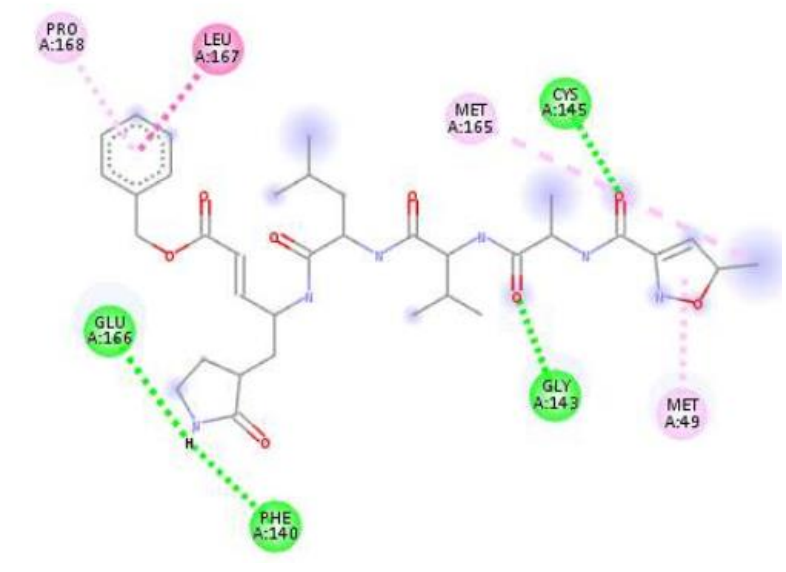

Interactions
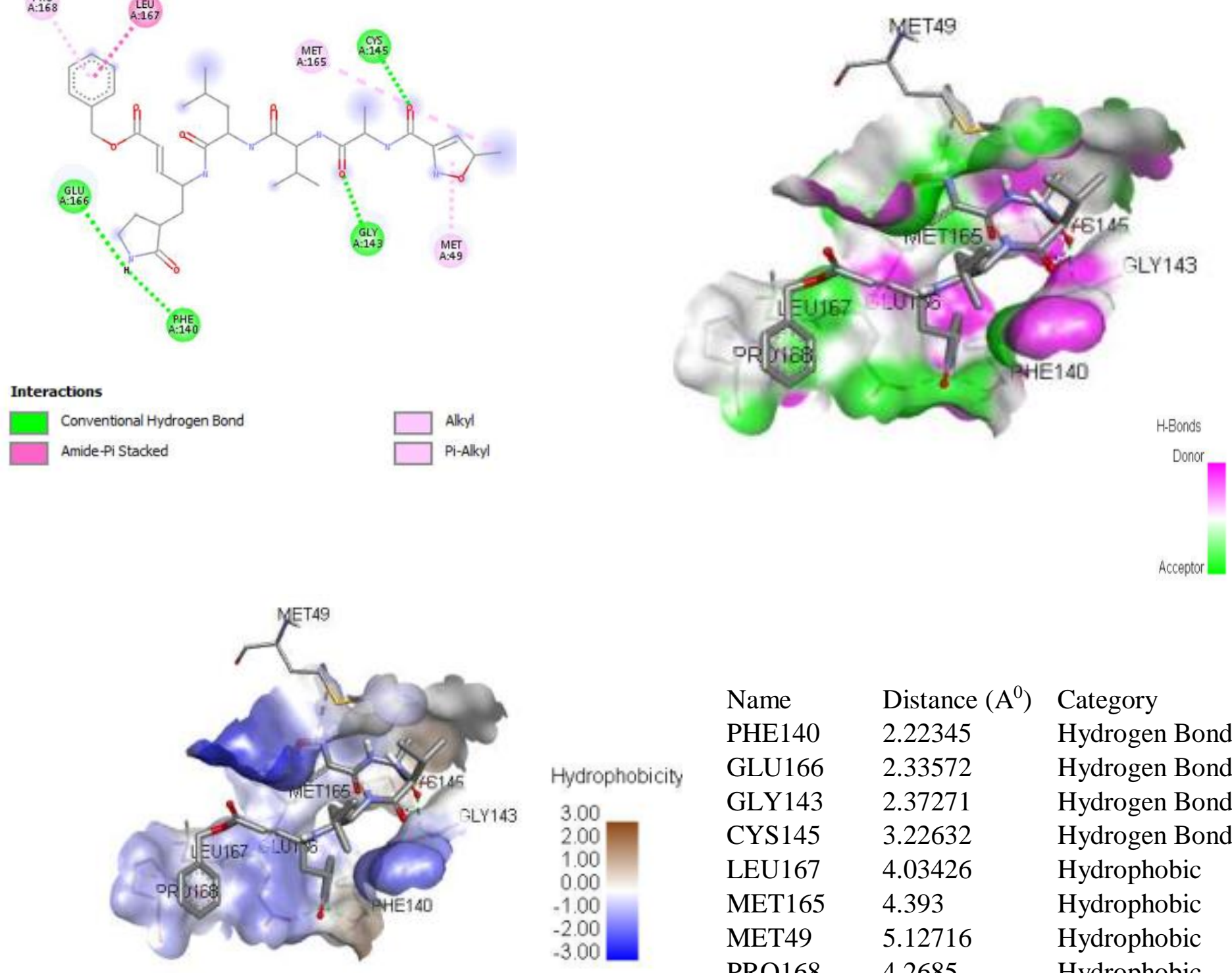

$\begin{array}{clll} & \text { Name } & \text { Distance }\left(\mathrm{A}^{0}\right) & \text { Category } \\ & \text { PHE140 } & 2.22345 & \text { Hydrogen Bond } \\ \text { Hydrophobicity } & \text { GLU166 } & 2.33572 & \text { Hydrogen Bond } \\ 3.00 & \text { GLY143 } & 2.37271 & \text { Hydrogen Bond } \\ 2.00 & \text { CYS145 } & 3.22632 & \text { Hydrogen Bond } \\ 1.00 & \text { LEU167 } & 4.03426 & \text { Hydrophobic } \\ 0.00 & \text { MET165 } & 4.393 & \text { Hydrophobic } \\ -1.00 & \text { MET49 } & 5.12716 & \text { Hydrophobic } \\ -2.00 & \text { PRO168 } & 4.2685 & \text { Hydrophobic }\end{array}$

Figure 5: Interactions of co-crystallized ligand, N3 over 3CLpro 